\title{
Desafíos teológicos de la opción preferencial por los pobres*
}

\author{
David Lima Díaz**
}

Recibido: 31 de octubre de 2017 • Aprobado: 30 de noviembre de 2017

\section{Resumen}

El concepto de opción preferencial por los pobres ha sido desarrollado recientemente por la teología latinoamericana y ha sido visto como una noción revolucionaria del siglo XX. Sin embargo, las Escrituras plantean que esta idea procede del amor de Dios, en especial, a los más necesitados. Por eso se hace necesario ofrecer, en unas breves pinceladas, cómo, a partir de la realidad social, política, económica y religiosa de Latinoamérica, la opción por los pobres tiene su sustento en las Escrituras, de manera que se pueda concluir que la opción preferencial por los pobres es una iniciativa del amor de Dios.

Palabras clave: pobres, teología, cristianismo, escrituras, moral, amor de Dios.

* Artículo desarrollado como reflexión académica de la Maestría en Teología, Facultad de Teología, Pontificia Universidad Javeriana, Bogotá. DOI: http://dx.doi.org/10.15332/s20119771.2017.0002.03

** Magíster en Teología, coinvestigador del grupo A-kasa: Teología y Mundo Contemporáneo de la Facultad de Teología, Pontificia Universidad Javeriana. Correo electrónico: dlima@javeriana.edu.co 


\title{
Theological challenges of the preferential option for the poor
}

\begin{abstract}
The concept of preferential option for the poor has recently been developed by Latin American theology and has been seen as a twentieth-century revolutionary notion. However, the Scriptures state that this idea comes from the love of God, especially, to the neediest. That is why it is necessary to offer, in a few brief descriptions, how, from the social, political, economic and religious reality of Latin America, the option for the poor has its sustenance in the Scriptures, so that it can be concluded that the preferential option for the poor is an initiative of the love of God.
\end{abstract}

Keywords: poor, theology, Christianity, scriptures, morals, love of God.

\section{Desafios teológicos da opção preferencial pelos pobres}

\section{Resumo}

O conceito da opção preferencial pelos pobres tem sido desenvolvido recentemente pela teologia latino-americana e tem sido visto como uma noção revolucionária do século XX. Porém, as Escrituras explicam que esta ideia procede do amor de Deus, em especial, aos mais necessitados. Por isso é necessário oferecer, em umas breves pinceladas, como a partir da realidade social, política, econômica e religiosa América Latina, a opção pelos pobres tem seu sustento nas Escrituras, de maneira que se possa concluir que a opção preferencial pelos pobres é uma iniciativa do amor de Deus.

Palavras-chave: pobres, teologia, cristianismo, escrituras, moral, amor de Deus. 


\section{Introducción}

La manera de vivir de la humanidad ha cambiado drásticamente en los últimos años y se puede percibir cómo diariamente se presentan transformaciones en la manera de hacer las cosas. La tecnología permite actividades que hace unas décadas eran impensables. Los habitantes de las diversas urbes se empeñan en una carrera sin fin por obtener los últimos avances: aparatos electrónicos que hacen un sinnúmero de maravillas. Delante de esta realidad tan cambiante surge una inquietud para quienes se empeñan en el seguimiento auténtico de Jesús: ¿por qué pensar y legitimar la opción preferencial por los pobres?

La pregunta por los pobres surge de una serie de teologías que nacen en América Latina, un continente con notables contrastes entre riqueza y pobreza. Recientemente han surgido posturas que deslegitimizan la necesidad de optar por los pobres, como si el propósito de la teología fuese defender dogmas milenarios. No obstante, la actualidad de este tema es motivo de reflexión: ¿será que este concepto es un invento de hombres y mujeres que han reflexionado su relación con Dios en las tierras del Nuevo Mundo o es más bien un legado de la tradición cristiana? Para tratar de resolver esta inquietud se intentará seguir tres pasos metodológicos para la Teología de la Liberación propuestos por Clodovis Boff (1990, pp. 79-113): la mediación socio-analítica, la mediación hermenéutica y la mediación práctica.

En el primer paso, la mediación socio-analítica, se indagan algunos rasgos que permiten desarrollar el concepto de la opción preferencial por los pobres en América Latina. ¿Qué significa hacer una opción preferencial por los pobres? ¿De dónde surge la necesidad de mirar al pobre como sujeto de la teología? ¿Es acaso una invención de ideologías filosóficas posmodernas las que motivan una opción por los pobres o el mero resultado de circunstancias sociales, políticas y económicas que modificaron la manera como se elabora la teología en Latinoamérica?

En un segundo paso, se tratará de comprender, por medio de la mediación hermenéutica, cómo las Escrituras fueron inspiradoras en el proceso de elaboración de esta noción, que surge, precisamente, del anuncio de la Nueva Alianza y que se concreta en la búsqueda del Reino de Dios. ¿Qué dicen las Escrituras acerca de la opción preferencial por los pobres? Finalmente, la mediación práctica tratará de establecer los desafíos teológicos que se desenvuelven de la opción preferencial por los pobres. La pregunta que dirige este último paso es: ¿cómo establecer prácticas que sean consecuentes con el seguimiento de Jesús por medio de la opción preferencial por los pobres? 


\section{Origen de la opción preferencial por los pobres}

Demos inicio al primer paso: ¿de dónde surge la necesidad de mirar al pobre como sujeto de la teología? ¿Por qué se haría necesario pensar en la opción preferencial por los pobres? La respuesta surge precisamente de los cambios estructurales que ha sufrido el mundo entero desde la Revolución Industrial, así como los cambios de paradigmas económicos, sociales y políticos, que han llevado a un alto consumismo: la tierra rica y diversa de los pueblos latinoamericanos se ha ido empobreciendo dramáticamente por causa del bienestar a corto plazo (Francisco, 2015, 34; Parker, 2014). Latinoamérica ha vivido una historia marginada, de opresión e injusticia. Las dictaduras de los años sesenta y setenta del siglo pasado llevaron a una reflexión sobre las causas estructurales de los hechos violentos que desde entonces se han venido presentando.

A lo largo de su historia, América Latina ha vivido el drama de la opresión por causa del enfrentamiento de culturas: la dominación de colonizadores que han empobrecido a sus gentes, sustraído sus riquezas y despreciado hasta la persecución a los vencidos (Moreno, 1986, p. 91). La discriminación, los trabajos forzados y las difíciles condiciones de culturas y razas diferentes en sus orígenes, pero que se dan a la tarea de construir una nueva vida. La modernidad europea es importada e impuesta al pueblo americano con graves síntomas de esclavitud, marginalización y exterminio de los más vulnerables (p. 92). Quienes vivían en estas tierras no se sentían identificados con los valores morales y religiosos que les habían sido impuestos.

La dificultad por crear sus propios estamentos llevó a los mestizos americanos a alojarse en la figura del Padre misericordioso. La religión en estas tierras fue impuesta "a las malas" como muchas otras buenas costumbres, aun así, con los años adquirió un nuevo tono. La religiosidad se impone como estructura de colonización, pero después se separa de cualquier institución social (Maduro, 1981, p. 94). La práctica religiosa se convierte en el nuevo escampadero donde los pueblos marginados sienten la seguridad de ser auténticos: “(...) debido a la escasez del clero, acabó siendo un medio singular de resistencia religioso-cultural, mediante la incorporación o adaptación de elementos precristianos" (Moreno, 1986, p. 94).

Con el análisis de las diversas condiciones que ha vivido América Latina se puede intuir qué ha llevado a sus habitantes a vivir situaciones de pobreza e injusticia. Las diversas ciencias sociales han aportado desde sus estudios datos que permiten entender qué ha pasado en América Latina para encontrarse en un 
ambiente de hostilidad donde se ha desarrollado la pobreza y un grave conflicto estructural, y la teología no se puede quedar callada ante esta dura situación (Libânio, 1989, p. 43). "Para la reflexión ética, este es un dato central a tener en cuenta sin que sea posible reducirlo a meros accidentes circunstanciales capaces de modificar los juicios morales" (Moreno, 1986, p. 93).

Delante de las angustias surge la pregunta por la causa de tales consecuencias. ¿Por qué hay tanto sufrimiento en un pueblo que ha sido marginado a lo largo de su historia? "Diversos estudios sociológicos analizaron nuestra situación social y concluyeron que esta injusticia que vivimos no era algo casual, sino causal" (Oliveros, 1989, p. 90). ¿Cómo se ha hecho presente Dios en toda esta problemática? Se requiere comprender la historia y las características de la reflexión moral para establecer las relaciones que han surgido, entender cómo son tales vínculos y proceder a tomar acciones que modifiquen la realidad de opresión (Moreno, 1986, p. 68).

Un estudio de la realidad permite comprender las condiciones que llevaron a los pueblos latinos a convertirse en víctimas de tantas injurias (Oliveros, 1989, p. 100). Las crisis sociales, políticas y económicas, las dictaduras militares de los años setenta y ochenta acontecidas en diversos países y sus consecuentes agresiones, torturas, asesinatos y desapariciones provocan una nueva vitalidad en el campo de la fe (Moreno, 1986, pp. 56-58). Los curas y religiosas que optaron por los pobres fueron vistos como comunistas (Oliveros, 1989, p. 94). “En efecto, ante la realidad de la opresión, el pueblo latinoamericano ha ido tomando conciencia progresivamente de que se trata de una alienación, de un negar su derecho a ser $y$ a vivir con dignidad" (Moreno, 1986, p. 68).

De ningún modo la teología debería aislarse ante un pueblo que sufre. Las situaciones de persecución que viven diversos actores eclesiales les lleva a comprometerse a fondo con la lucha por los pobres, incluso al punto de asumir el martirio (p. 57). Los teólogos recuerdan la relación tomista que existe entre teología y moral. "De esta manera queda patente que es la teología el fundamento y el sustrato del que emerge la ética cristiana" (p. 84). Las preguntas que emanan de las clases marginadas sobre la situación que viven son leídas a la luz de las Escrituras. “Jesús nació, vivió y evangelizó en pobreza y solidario con los pobres (Puebla, 190)" (Oliveros, 1989, p. 101).

La crisis de Latinoamérica ha sido vista a la luz de las Escrituras por diversas comunidades eclesiales. Obreros, campesinos, estudiantes, amas de casa y religiosas han visto cómo las Escrituras iluminan sus vidas y dan respuesta a 
los cuestionamientos que han ido surgiendo por causa de la continua violencia. Es así como desde los años sesenta y setenta surgieron movimientos como las Comunidades Eclesiales de Base (CEB), asambleas familiares o casitas de oración donde conjuntos de vecinos se reúnen para leer las Escrituras. Se trata de lecturas críticas con las cuales las diversas comunidades, víctimas de las injusticias y la explotación, han reflexionado sobre la presencia de Dios, han sentido esperanza en el mensaje salvífico y su permanencia al lado de quienes sufren.

La Iglesia reconoce que las Escrituras señalan la obligación por el cuidado de los pobres como opción vital de la búsqueda del Reino de Dios. El Reino de Dios es construido por los pobres que encuentran a Cristo sufriente en el otro. La opción preferencial por los pobres tomó bastante importancia en la antesala del Concilio Vaticano II, cuando diferentes movimientos eclesiales, principalmente de América Latina, se pronunciaron bajo la necesidad de configurar aquello que Juan XXIII, citado por Libânio (1989, p. 69), llamó “Iglesia de los pobres" (Comblin, 1990, p. 637). El papa Juan XXIII sentía que el lugar teológico de la Iglesia debía ubicarse en medio de los pobres (Libânio, 1989, p. 69).

Varios obispos motivados por monseñor Hélder Câmara vieron la necesidad de ser consecuentes con la pobreza como opción de vida. El Pacto de las Catacumbas, que data de 1965, fue la declaración de compromiso en la opción de pobreza firmada por más de setenta obispos conciliares, principalmente latinoamericanos. "El documento es un desafío a los 'hermanos en el Episcopado' a llevar una 'vida de pobreza', en una Iglesia 'sierva y pobre', como sugerirá el Papa Juan XXIII" (Revista IHU, 2009). Un paso interesante en una sociedad que le rinde culto a la riqueza y al poder.

La opción preferencial por los pobres influyó en el cristianismo de América Latina de modo que se convirtió en una exigencia moral. Las Escrituras insisten en la predilección de Dios por los más necesitados y el cristianismo está llamado a asumir el proyecto de Dios. El desafío de optar por los pobres es una aplicación concreta de la teología latinoamericana que trata de aproximarse al Reino de Dios. Las condiciones de opresión vividas por obreros, campesinos y gente del pueblo, de los barrios y favelas, fueron motivo de inquietud frente a temas como la distribución de la riqueza y el acomodamiento de unos pocos. Las Escrituras iluminan la vida y muestran la misericordia de Dios. En ellas se percibe cómo la opción preferencial por los pobres ha sido considerada un deber moral en el seno del Pueblo de Dios (Lohfink, 1998, p. 31).

\section{Universidad Santo Tomás, Facultad de Teología}




\section{Algunos aportes de las Escrituras al concepto de la opción preferencial por los pobres}

En el segundo paso metodológico de la Teología de la Liberación, Clodovis Boff se pregunta cómo se puede interpretar la realidad a partir de la Escritura. La propuesta consiste en un ejercicio hermenéutico que se construye en el sólido cimiento aportado por el depósito de la fe: las Escrituras, la Tradición y el Magisterio que tienen como propósito acercar al creyente al Misterio de Dios. Para lograr una comprensión de los desafíos teológicos que ofrece la opción preferencial por los pobres se hace necesario ver qué dicen las Escrituras. El interés es presentar brevemente algunos hitos relevantes de la opción preferencial de Dios por los pobres presente tanto en el Antiguo como en el Nuevo Testamento.

\subsection{Antiguo Testamento}

Los cristianos reconocen en el Antiguo Testamento la manifestación de Dios en la historia humana. "El 'tiempo de Israel' es, sin lugar a dudas, el más largo y el que está representado por un extenso material literario" (Croatto, 1995, p. 31). Los escritores advierten que Dios no olvida el sufrimiento y que Él permanecerá al lado de los pobres en sus luchas y dificultades. "La promesa, orientada esencialmente hacia el futuro, supone un plan de salvación" (p. 42). El plan de salvación es el desarrollo de la voluntad divina en la historia humana para congregar a todos los creyentes "en una Iglesia universal en la casa del Padre" (Concilio Vaticano II, 1968, 2).

\subsubsection{Moisés y el Éxodo}

Los judíos, por diferentes circunstancias históricas, terminaron bajo el dominio de los egipcios, extraditados de su tierra, presos por el poder explotador de extranjeros, sin garantías de futuro; se empobrecieron. Dios tiene piedad de los judíos y establece la alianza con su Pueblo como señal de esperanza. "La alianza no es ya solamente un pacto (synthéké), sino un favor divino, una gracia" (Gelin, 1963, p. 48). La liberación se presenta como la opción de Dios frente al sufrimiento del ser humano. La Tierra Prometida es el sueño comparable a la nueva vida. No es fruto de una decisión particular, sino la construcción comunitaria de un colectivo que reconoce el deseo de emprender la solución a sus problemas; pero es, en todo caso, "la iniciativa del Señor". 
Moisés es una figura representativa en la opción preferencial de Dios por los pobres. De origen judío, Moisés encontró el favor de la hija del faraón. Adoptado por ella, creció en el ambiente de la nobleza. No obstante, cuando adquirió consciencia de la realidad que vivía su país, descubrió sus orígenes y percibió las injusticias cometidas. "Moisés es el protagonista humano del éxodo, llamado por Dios para llevar a cabo su acción liberadora (Ex 3,8-10; cf. 6, 13.26-27)" (García López, 2004, p. 145). De la mano de Dios Moisés encuentra el camino para liberar a los pobres azotados por el dominio egipcio. La salida debe ser por la vía de la paz, de la espera, de la perseverancia.

El Éxodo es un relato que identifica el momento de sufrimiento y desolación en el nuevo exilio y pretende mostrar que el hombre debe reconocer sus errores, responsabilizarse de sus actos, asumir las consecuencias y cambiar las actitudes que corrompen el orden establecido por Dios. “Más allá de la desgracia material que provocaron estos acontecimientos, se adivina la profundidad de la crisis moral que sacude al pueblo en estos momentos y del cuestionamiento de su confianza en Yahvéh" (Vermeylen, 1990, p. 123). ¿Cómo es posible que Dios opte por un pueblo esclavo y marginado? ¿Qué ganaría Dios con liberar a los judíos del poder de los egipcios? "El acontecimiento del éxodo tiene una magnitud mayor de lo que pueden pensar las víctimas del sistema que son liberadas en este acontecimiento" (Lohfink, 1987, p. 34). Sin duda es una iniciativa del amor de Dios para los más pobres.

\subsubsection{Los profetas}

Los profetas, como mediadores entre Dios y los hombres, observaron las condiciones históricas, sociales, económicas, políticas y teológicas de su cotidianidad (Sicre, 1998, pp. 249-260). “La experiencia de Dios es fundamental, aporta una visión totalmente nueva del mundo y de las relaciones con él” (p. 138). Sin dudar, la comunidad reconoce la autoridad de los profetas porque buscan el beneficio social y ético de la sociedad. "Los profetas llegan a identificar clara y explícitamente el conocimiento de Dios con la práctica real de la justicia a favor de los pobres, oprimidos y excluidos" (Fernández, 2007, p. 37) Los profetas fundamentan sus acciones en una búsqueda ética y teológica.

Esta actitud marca una clara diferencia con los falsos profetas que hablan para favorecer o satisfacer los intereses particulares de sus contratantes (Sicre, 1998, p. 145). Los verdaderos profetas juzgan los comportamientos que atentan contra el cuidado de los pobres y confrontan directamente a aquellos que 
frecuentan el templo para ofrecer grandes cultos y finos holocaustos (Fernández, 2007, p. 39). Estas costosas prácticas rituales se habían convertido en la manera como nobles y ricos se enorgullecían delante de los demás. Sin embargo, resulta evidente que estamos frente a cultos vacíos que satisfacen deseos particulares.

Antes del exilio de Israel ya se presentaban dificultades en la práctica del derecho y de la justicia. En la concepción equivocada de la teología de la retribución y en su posición como "pueblo escogido" por Dios, se cometen actos que no corresponden a la voluntad del Señor. La promesa a Abraham incluye tres bendiciones para los judíos: tierras, descendencia numerosa y vida larga. Quien cumpla con las leyes será premiado, quien falte es un maldito. "Esto ha ido induciendo la convicción de que solo en la tierra es posible al judío vivir plenamente como tal; de hecho, la destrucción del templo y el exilio fue interpretado por la voz profética como castigo por la infidelidad a la Alianza" (Sánchez, 2015, p. 394).

Los jueces, benevolentes con los ricos, no cumplían su papel judicial: daban dádivas a los ricos y convertían en esclavos a los pobres que no pudiesen pagar las tasas (Am 5,10-12). El abandono de las viudas, de los huérfanos, de los marginados y la explotación de los campesinos era una práctica cotidiana (Jr 7,6-7; 22,3). "Muchas leyes particulares miraban expresamente a ayudar a estas clases sociales" (García Trapiello, 1977, p. 90). Lastimosamente estas prescripciones no eran cumplidas y de ahí la denuncia profética de abusos como los préstamos con intereses, los salarios injustos y retrasados, la opresión de los siervos y otras prácticas que favorecían a los poderosos (p. 90-95).

Los profetas hacen grandes aportes en la opción preferencial por los pobres en la medida que denuncian las situaciones injustas. La violación de las leyes es percibida como una falta grave contra la teología de la alianza establecida entre Dios y el pueblo (Sicre, 1986, p. 93). En ese momento histórico no es posible desvincular una dimensión de las demás: una decisión política trae consecuencias económicas, sociales y religiosas. Los profetas muestran la difícil realidad de pobres y marginados que surgen por causa del incumplimiento de la Alianza. Hay que entender que al aceptar la Alianza se hace evidente el estricto cumplimiento de las leyes (Sicre, 1985, pp. 149-152).

\subsubsection{Amós}

Procedente del Reino del Sur, Amós cumple su misión en el Reino del Norte (Schökel y Sicre, 1980b, p. 953). Allí denuncia los actos injustos e interpela sobre el sentido de la paz vivida por algunos (Am 5,18) que creen que con una fiesta 
litúrgica obtendrán el favor del Señor (Schökel y Sicre, 1980b, p. 979). La lectura de la realidad hecha por el hijo de Tecua concuerda con la teología de la retribución, porque los poderosos de su tiempo creían que el sentimiento de paz vivido en aquellos años era una bendición de Dios (Am 6,1-7). Por el contrario, esa tranquilidad es solamente de los ricos, pues los menos afortunados sufren mucho por causa de ellos (Am 5,12; 6,12).

Amós critica duramente a las instituciones comerciales que practican las injusticias con los pobres y miserables (Am 8,4-7; Schökel y Sicre, 1980b, p. 987). "Para estos comerciantes, el día de fiesta es una interrupción del negocio, una pérdida" (p. 988). También recuerda la responsabilidad que tienen los habitantes por haber sido escogidos como Pueblo de Dios (Am 9,7), el deber de cumplir la Alianza, olvidar dioses extranjeros y la obligación con los pobres, desvalidos y marginados (Am 9,11-15; Vitório, 2003, pp. 125-143). “La elección y la liberación fundacional son dones que crean exigencias; de nada vale la elección si el pueblo la anula con su pecado" (Schökel y Sicre, 1980b, p. 992).

\subsubsection{Miqueas}

Miqueas acusa a los responsables de la fractura social en Israel: habla contra los jefes que juzgan por soborno, los sacerdotes que deciden por salario y los profetas que vaticinan por dinero (Miq 3,11). Denuncia la explotación de las mujeres y sus hijos, la esclavitud infantil, las ilegalidades de los comerciantes que engañan con medidas falsas y los actos de individualismo y las injusticias de los ricos (Sicre, 1998, p. 299). Los marginados y oprimidos llevan las mayores cargas y tienen que pagar con su libertad el precio de las infamias. La realidad en Israel es desalentadora; no obstante, el profeta tiene esperanzas de salvación en el Señor (Suaiden, 2007, pp. 121-139).

El pueblo solo tiene una vía de salvación: practicar la justicia, amar la bondad y acoger al Señor en la cotidianidad (Miq 6,8). Dios reunirá de nuevo al pueblo disperso. El Señor siente la misma responsabilidad por Israel como un pastor la siente por su rebaño y cuida de cada una de sus ovejas. Nacerá en poco tiempo un líder que guiará y llevará a Israel a la victoria (Sicre, 1986). No obstante, esa intervención del Señor exige cambios en las actitudes de los israelitas. Dios no tolera las actitudes que están aconteciendo en su pueblo y pide una profunda conversión. "Por eso, Miqueas no se enfrenta solo a una serie de injusticias, sino a una 'teología de la opresión'” (Sicre, 1998, p. 299).

\section{Universidad Santo Tomás, Facultad de Teología}




\subsubsection{Jeremías}

Jeremías vive en Israel cuando acontece un cambio de gobierno. Con el rey Josías la reforma religiosa abolió el baalismo en Israel y recuperó las prácticas piadosas enseñadas por el Código Deuteronomista. El cumplimiento de la reforma era señal de esperanza y llevaba a la conversión de Israel. Sin embargo, cuando murió Josías, su hijo Joaquín ascendió al trono después de un breve gobierno de su hermano Joacaz (Schökel y Sicre, 1980a, p. 401). Las circunstancias de bienestar cambiaron significativamente (Jr 22,15-19). Un alto tributo perjudica el bienestar de Judá (Schökel y Sicre, 1980a, p. 401). El profeta denuncia las prácticas asumidas tanto por el nuevo rey como por la población (Jr 5,28). Jeremías reprobaba la despreocupación gubernamental en el cuidado de la ley (Amsler et al., 1992, pp. 41-141).

La decisión de construir un palacio y obligar a las personas a trabajar gratis era actuar en contradicción de la ley del Señor (Jr 22,13). "Al denunciar valientemente los crímenes del rey, el profeta nos da una admirable lección teológica" (Schökel y Sicre, 1980a, p. 516). Jeremías denuncia los actos pecaminosos: "robar, matar, cometer adulterio, jurar falso, incensar a Baal" (Jr 7,9) que eran seguidos de ceremonias litúrgicas en el templo del Señor. Así, si parecía que por el solo hecho de asistir al templo y ofrecer incienso se estaba cumpliendo la voluntad del Señor, los judíos estaban equivocados en su concepto de práctica religiosa (Schökel y Sicre, 1980a, p. 455). El deber ético del cuidado de los pobres, la práctica de la justicia y los actos de misericordia son las actitudes que alegran al Señor (Jr 22,1-5; 16,49,13).

\subsection{Nuevo Testamento}

Las primeras comunidades cristianas tienen plena consciencia de que la opción preferencial por los pobres es una exigencia en el seguimiento de Jesús. Las fuertes disputas que tienen los cristianos con las estructuras sociales ofrecen el telón de fondo para que las comunidades se cuestionen por el significado y la centralidad de Jesucristo. Pikaza y De La Calle afirman que la palabra de Jesús es de doble contenido: “Por un lado es 'palabra de Evangelio' que proclama que Jesús, la salvación de Dios, se encuentra en los pequeños de la tierra, en los que tienen hambre y sed, están desnudos" (1980, p. 121). Por otro lado, Jesús es plenitud de las personas que han arriesgado su vida en el cumplimiento de la ley del amor al prójimo. 
La vida de Jesús promueve un giro en la manera de comprender las relaciones humanas. "Frente a la desilusión total de aquellos que no entienden la victoria de Jesús partiendo de su vida en Galilea acude Lucas al valor y testimonio de las viejas escrituras" (p. 318). Delante de la muerte del hijo de María, las comunidades estarían en una confusión y probablemente no lograban comprender el sentido de la vida del nazareno. ¿Dónde se realizan las esperanzas de la comunidad? ¿En dónde quedaron las promesas? “¿Es cierto que Jesús se ha aparecido? ¿No fueron todo unas visiones?" (p. 319).

Esas y otras preguntas pueden haber surgido en la tradición oral, antes de la elaboración de los textos. Aun así, los conflictos no son solamente con las estructuras externas. La Primera Carta a los Corintios, por ejemplo, muestra que hacia la primera mitad del primer siglo esa comunidad ya presentaba problemas de desunión y división entre los cristianos por causa de los bienes materiales (Barbaglio, 1995, pp. 22-36). "La Iglesia se siente afectada en cada uno de sus miembros, pero por misteriosas razones, de modo muy especial en los pobres" (Walter, 1971, p. 205). El Nuevo Testamento se preocupa porque los cristianos asuman un compromiso ético en favor de los más necesitados.

\subsubsection{Los Evangelios}

La perspectiva de cada evangelista en relación al tema de la pobreza es diferente por causa de las circunstancias en las cuales fue pensada cada catequesis. "Cada uno de los cuatro evangelistas nos da una visión completa de toda la realidad cristiana, aunque cada autor lo haga desde su propio ángulo y problemática" (Pikaza y De La Calle, 1980, p. 12). Los Evangelios sinópticos alientan a las comunidades que sufren la exclusión de los pobres por parte de las diferentes fuerzas de poder. "Los 'pobres' son personas incapaces de conservar en la sociedad su estatus de honor heredado, por la mala suerte o por la injusticia de los demás" (Malina y Rohrbaugh, 1996, p. 393). La pobreza sugiere otro tipo de condiciones a las vividas actualmente.

Sin embargo, aunque las condiciones son diferentes, y para evitar los anacronismos, hay que entender que la pobreza no es una cuestión únicamente material. "Lo que hace a una persona pobre es el infortunio social más que el económico" (p. 393). De esta forma, Malina y Rohrbaugh explican que una viuda sin hijos, un paralítico o un pagano podrían tener bastantes tierras y dinero, pero igual son pobres para la sociedad dado su carácter de vulnerabilidad (p. 393). La comunidad cristiana no puede ser indiferente al dolor de estas personas. Los 
evangelistas descubren fisuras sociales ante las cuales la figura de Cristo es motivo de salvación.

Con los Evangelios la Iglesia naciente toma consciencia de su misión ética a partir de la Revelación que acontece en Cristo manifestado en el evento pascual (Schrage, 1987, p. 148). Pero no solo es la pasión, la muerte y la resurrección; sus actos demuestran a una comunidad en crisis que es prioridad atender a las víctimas de las injusticias; porque si los gobernantes y los grandes tiranizan a las naciones, los cristianos están llamados a practicar la caridad y servir a los necesitados (Mt 20,25-27). "Por esto la comunidad cristiana comunica y anuncia a este Jesús que asume al hombre y su historia, haciéndose uno de nosotros para comunicarnos nuestra plenitud" (Novoa, 2009, p. 33).

Hacia el siglo I d. C., los habitantes de Palestina vivían bajo el dominio del Imperio Romano (Marcus, 2010a, pp. 47-52) y las estructuras locales buscaban mantener su poder en las instancias permitidas por el emperador (Sicre, 1996b, pp. 279-297). El pueblo judío aguardaba el nacimiento de un mesías guerrero, un héroe que organizaría los ejércitos, los libertaría de la opresión imperial y traería un nuevo reinado (Sicre, 1996a, pp. 240-241). No obstante, las comunidades cristianas descubren que la dinámica propuesta por Jesús tiene otras características que no se ajustan a las exigencias sociales.

\subsubsection{Marcos y Lucas}

La opción de Jesús por los pobres atraviesa vida, enseñanzas, acciones; es el modo como Cristo se relaciona con el Padre. Marcos y Lucas serán muy similares en este asunto. El Hijo es enviado a anunciar la Buena Noticia a los pobres (Lc 4,18). Enfermos, extranjeros, marginados, viudas y huérfanos son pobres por causa de su situación de exclusión de una sociedad rígida en las leyes. La falta de condiciones dignas crea pobreza y Jesús siente la urgencia de aliviar esas dificultades. "La Iglesia hace propios estos sufrimientos y anhelos solidarizándose con ellos, encontrando en la persona de Jesús la liberación plena de todos estos padecimientos y la verdadera realización del hombre latinoamericano" (Novoa, 2009, p. 33).

El Reino de Dios pertenece a los débiles y a aquellos que los cuidan (Mc 10,13-16). Por tanto, la promesa hecha por los profetas del Reino prometido requiere de una nueva hermenéutica, es decir, una "inversión, con la cual Jesús favorece al despreciado sobre el estimado" (Marcus, 2010b, p. 825). El cristiano está llamado a vivir la inversión de los valores presentes en la sociedad para orientar 
una nueva manera de proceder con el prójimo. El Reino que Jesús anuncia no tiene nada que ver con la derrota y expulsión del Imperio romano. De hecho, Jesús respeta las estructuras de poder establecidas en la región (Mc 12,13-17).

La inversión que Jesús propone es, en realidad, en el comportamiento humano. No es suficiente el cumplimiento de la ley; el compromiso con los pobres es una obligación para acceder al Reino de Dios (Mc 10,19-22). La opción por la pobreza no es una mera cuestión material. "Solo Dios es la riqueza verdadera; por eso, el que se encuentra lleno de sí mismo, el que pretende asegurar su vida desde el mundo, en realidad está vacío y es hambriento" (Pikaza y De La Calle, 1980, p. 238). La salvación acontece para los pobres porque ellos corresponden al amor de Dios. La comunidad lucana tenía consciencia del papel soteriológico de Jesús (Lc 2,10-11) que es muy diferente del anuncio de un potentado o gobernante terrenal (Pikaza y De La Calle, 1980, p.238).

Jesús nació pobre, en una pesebrera (Lc 2,1), hijo de un artesano; escogió como discípulos a pescadores (Lc 5,8-11), cobradores de impuestos (Lc 5,27; Mc $2,14)$, personas rechazadas por las altas sociedades. Jesús compartía su vida con los pobres: come con ellos en sus casas (Mt 9,10; Lc 5,30), es compasivo con la multitud que no tiene qué comer (Mc 8,2) y siente compasión por los sufrimientos de los necesitados (Mc 6,53-56; Mt 9,36). La preferencia de Jesús por los pobres en los sinópticos no corresponde a la imagen que los judíos esperan del Salvador; no obstante, la propuesta del "Reino de Dios" que anuncia Jesús es el cumplimiento de la Promesa de Dios (Novoa, 2009, p. 34; Sicre, 1996b, pp. 304-306).

El mesianismo de Jesús debe ser comprendido en la coherencia con la entrega y el sacrificio (Novoa, 2009, p. 112). La gloria del Señor se presenta para quien se hace servidor de los otros y consigue establecer relaciones familiares con los demás (Mc 10,37; 41-45. Pikaza y De La Calle, 1980, p. 77). La opción por el Reino de Dios significa asumir los sacrificios con alegría; es decir, entrar por la puerta estrecha y no tener miedo de perder los privilegios recibidos con anterioridad (Lc 13,24; Pikaza y De La Calle, 1980, p. 289). Para Jesús las ofrendas valiosas son como el óbolo de la viuda (Mc 12,41-44): ella dona de aquello que requiere. La insistencia por la misericordia, proclamada por los profetas, es realzada por Jesús: "Sean pues misericordiosos, como también vuestro Padre es misericordioso" (Lc 6,36).

La misericordia, la entrega y el sacrificio conducen al cumplimiento de la ley más esencial: el primer mandamiento. “El gran mandamiento cristiano es doble: amor a Dios y al prójimo; los dos al mismo rasero de valor. Esta es la contrapartida al nacionalismo judío (Mc 12,28-34)" (Pikaza y De La Calle, 1980, p. 81). El amor a Dios debe tener consecuencias prácticas: orar por los autores de 
calumnias e injurias, aceptar los oprobios de los enemigos, ejercitar el amor a los enemigos, prestar sin condiciones y hacer el bien. En pocas palabras, la opción por los pobres conlleva una serie de actitudes humanas agradables al Señor que Lucas logra aclarar con ejemplos (Lc 6,27-35; Pikaza y De La Calle, 1980, p. 261).

\subsubsection{Mateo}

Mateo aborda el tema de una manera particular cuando hace una elección por los más pequeños y débiles (Aguirre, Bernabé y Gil, 2014, p. 47-50). La comunidad de Mateo, de origen judaico, es motivada para reflexionar en torno a la propuesta del templo y las leyes judías (pp. 15-18). La elección del Pueblo de Israel trae desafíos que deben ser asumidos con responsabilidad. Juan no atiende la cuestión de la pobreza del mismo modo como ocurre en los tres primeros Evangelios. Juan se encuentra en una sociedad que, probablemente, tiene mejor calidad de vida. Pero, no por eso quiere decir que en Juan la opción por los pobres esté ausente.

La catequesis de Mateo en relación a la pobreza es amplia y considera varias actitudes como el desprendimiento, la confianza en la Providencia y la oración (Pikaza y De La Calle, 1980, p. 145). El desprendimiento comienza con la consciencia de que el dinero es un medio para servir los otros, pero cuando se convierte en el objetivo de la vida se puede equiparar a otro dios. Nadie consigue, por tanto, servir a dos señores (Mt 6,24). "Solo el reino es el auténtico tesoro de los hombres. Todo ha de quedar a su servicio" (Pikaza y De La Calle, 1980, p. 142). Los ricos deben entender que los bienes materiales deben ser colocados a disposición del servicio a la comunidad; no son para ser acumulados (Mt 6,19-33).

La actitud de abnegación aproxima a los hombres al Señor; pero la generosidad debe acontecer en secreto, porque quien divulga su limosna recibe el beneplácito de los hombres, no del Señor: "La limosna que se da en ayuda al indigente no se puede convertir en propaganda (Mt 6,2-4)" (Pikaza y De La Calle, 1980, p. 144). Mateo, así como Lucas, insisten en el abandono a la Providencia (Mt 6,25-34; Lc 12,33-34; Lc 10,21-22). Los pobres son ejemplo de tal gesto. Mateo consigue inspeccionar el dolor y sufrimiento de los oprimidos (Pikaza y De La Calle, 1980, p. 145). El abandono a la Providencia reconfigura la oración como relación del hombre que deposita todas sus necesidades en Dios (Mt 7,7-10).

El ser humano debe aproximarse al Señor en actitud humilde y silenciosa, orante, con deseo de recibir y conceder perdón (Mt 6, 9-15). Las personas tienen el desafío de aprender a depender de Dios porque el Señor cuida de quienes le aman (Pikaza y De La Calle, 1980, p. 145). No obstante, la enseñanza más 
relevante de la catequesis de Mateo es la configuración del Reino, el cual se encuentra en los discursos inaugural y escatológico. En el primero, constituido por el sermón de la montaña, Jesús educa en los comportamientos que llevan al ser humano hacia la búsqueda del Reino. "Ser cristiano quiere decir ser discípulo" (Schrage, 1987, p. 176).

En las bienaventuranzas (Mt 5,1-12; Lc 6,20-26) Jesús se dirige a los pobres: los hambrientos, afligidos, perseguidos, las personas sin protección, privados de seguridad material y social. Todos ellos viven "el ideal de vida de los discípulos de Jesús" (Aguirre, Bernabé y Gil, 2014, p. 20). La presencia de Dios y el motivo de felicidad de los pobres no es por la condición social que es precaria, sino porque Jesús anuncia la llegada del Reino. “El Reino ya se acerca, está a las puertas. Los pobres y oprimidos solo tienen que venir a recibirlo" (Pikaza y De La Calle, 1980, p. 141). Los pobres son felices porque serán consolados, saciados de sus dificultades, su mansedumbre les heredará la tierra, alcanzarán misericordia; Dios toma la defensa de los pobres y el reino les pertenecerá (Mt 5,3).

El discurso escatológico es la conclusión de la catequesis de Mateo. La comunidad quiere conocer cuándo acontecerá el final de los tiempos (Mt 24,3). La respuesta de Jesús considera la situación de los movimientos apocalípticos que pretenden marcar una fecha de cuándo acontecerá el juicio final (Luz, 2003, pp. 529-530). Si en el discurso inaugural el evangelista proclamaba la venida del Reino de Dios, y en los discursos siguientes profundizó en los temas eclesiales, en la formación de la comunidad y en la misión y las actitudes propias de los cristianos (Pikaza y De La Calle, 1980, p. 195), ahora el punto es mostrar la tensión escatológica del "ya, pero todavía no" en el cual acontece el Reino.

El Reino de Dios ya acontece para aquellos que son misericordiosos y compasivos con las necesidades de los desfavorecidos (Mt 25,31-46; Luz, 2003, pp. 692-694). El mensaje es mantenerse vigilantes como el mayordomo que no conoce la hora en que llegará su señor. Son las actitudes de cuidado de los otros que acercan el Reino; ellos gozan de la gracia de Dios y tendrán la vida eterna. "Para la ética de Mateo es fundamental la vinculación con la persona y con la obra de Jesús" (Schrage, p. 175). Por eso, quien no se preocupa con los pequeños será juzgado y castigado. El Reino, entonces, no es un lugar geográfico; es una realidad transcendental a la que se accede por un comportamiento ético en favor de los demás.

\subsubsection{Juan}

El cuarto Evangelio está probablemente dirigido a la sociedad urbana helenista en el final del siglo primero. Para Juan el mundo de los pobres no tiene mayor

\section{Universidad Santo Tomás, Facultad de Teología}


importancia: "la pobreza y el uso del dinero no son la preocupación primordial de Juan" (Konings, 2005, p. 38). Las amistades que acompañan a Jesús tienen relativa estabilidad económica. No obstante, "el cuarto Evangelio incluye naturalmente el cuidado de los pobres" (p. 39). El Jesús de Juan enfatiza el deber de dar limosna (Jn 13,29), el amor fraterno comunitario (Jn 13,34-35) y el servicio mutuo (Jn 13,14). El lavado de los pies es la señal de abajamiento y cuidado del otro.

La pobreza en Juan no se limita a la imposibilidad de tener bienes. "El excluido se convertía en un paria, una persona sin referencia social, sin protección y sin lastro económico" (Konings, 2005, p. 39). Jesús busca a los excluidos, sea por sus dolencias (Jn 5,2-8) o por su realidad social (Jn 4,4-40). La exclusión de la comunidad es otro modo de pobreza. Ir al encuentro de los excluidos de la comunidad es cuidar de los pobres (Konings, 2005, pp. 38-39). Jesús no solo tiene una clara opción por los pobres, Jesús se encuentra del lado de los pobres porque tiene una opción fundamental ético-teológica.

\subsubsection{Pablo}

En Corinto, el apóstol Pablo llama la atención a las pequeñas comunidades cristianas que no logran mantener la unidad en Cristo y compartir el pan con el necesitado (1Cor 11,20-23; González, 1988, pp. 75-79). “Los cristianos son una minoría en esa ciudad y pertenecen a las capas más pobres de la población, lo cual no impide que haya entre ellos desigualdades de fortuna que pueden dar lugar a graves abusos al celebrar las reuniones" (Martimort, 1987, p. 313). Compartir el pan no se limita a una celebración particular; la exigencia de los cristianos es vivir esa entrega en la vida cotidiana y ser, así, testigos vivos del amor de Dios a los hombres. "El consejo que da el apóstol es que ningún tipo pretenda suprimir al otro" (González, 1988, p. 74).

Pablo critica fuertemente la falta de caridad que se presenta en la comunidad (p. 75). El apóstol se vio obligado a llamar la atención de la comunidad de Corinto por causa de las divisiones entre ellos. La crítica de Pablo se centra en las dificultades de vivir la comunión (1Cor 11,20-22; Barbaglio, 1993, pp. 77-78). Los ricos de Corinto olvidaron el sentido libertador de la enseñanza de Jesucristo en la donación de su cuerpo y su sangre. El espíritu de partir y comer el pan de Cristo debe ser "memoria que impone obligaciones a quien celebra la eucaristía" (Barbaglio. 1993, p. 78).

La vida en común implica diferentes aspectos de entrega que deben buscar la vivencia del Reino de Dios. "Pablo parece interpretar el amor al prójimo como 
amor fraterno" (Stegemann y Stegemann, 2001, p. 377). Los cristianos motivan un cambio estructural en las sociedades donde participan. El compromiso con el pueblo se convierte en esencial para las primeras comunidades, no por causa de su poder político, sino porque en su historia se reconocen pobres y, por consiguiente, no pueden ignorar el deber ético que Dios les manifiesta (Theissen, 2002, p. 117). Del Señor procede el llamado de participar los bienes con los pobres, celebrar el memorial enseñado por Jesucristo y aceptar las persecuciones que por causa del Evangelio se causen (Ef 3,1-13; Barbaglio, 1992, p. 237).

Las epístolas paulinas tienen como sentido aproximar a los cristianos a la experiencia ética de la vivencia del Evangelio, orientarlos a una nueva realidad contracultural y fortalecer el aspecto comunitario que debe buscar el bien común. Será necesario modificar la actitud de los gobernantes hacia una práctica del cuidado fraterno (Flp 2,1-4; González, 1988, p. 100). El hijo de Tarso exhorta en la práctica de la caridad con los desfavorecidos realizada con profundos sentimientos de amor. "Dicho en otras palabras, por la gracia liberadora del Dios de Jesucristo el creyente es un ser operativo nuevo que se mueve según la dinámica sobrenatural del amor (agapē) (1Cor 13,3)" (Barbaglio, 1992, p. 204).

Esos sentimientos deben ser aprendidos del ejemplo del Jesús que, aun siendo de condición divina, se hizo servidor y se rebajó para donarse totalmente; de igual modo los señores no tienen otra opción que seguir el ejemplo de Cristo (Flp 2,5-8; González, 1988, p. 101). La comunidad debe propiciar el cuidado de los débiles y marginados: los maridos deben cuidar de sus mujeres y amarlas con bastante celo (Ef 5,25), los padres deben cuidar y educar los hijos (Ef 6,4), la comunidad debe cuidar de las viudas (1Tm 5,3). El desafío consiste en el compromiso frente a los demás: porque si por la gracia de Dios los seres humanos somos rescatados de la esclavitud, es gracias a que Dios nos concede el derecho de considerarnos sus hijos (Gal 4,1-11), para que el amor sea practicado los unos con los otros.

\subsubsection{Santiago}

La Carta de Santiago tiene varias referencias interesantes a la inquietud de la opción por los pobres. La elección de la pobreza será condicional para acceder al Reino de Dios. Santiago exalta la pobreza como opción espiritual y de libertad para afrontar las pruebas que la vida presenta (Sant 1,12). No obstante, confronta las actitudes que marginan injustamente a los pobres; las injusticias, los abusos de autoridad y la falta de caridad de los ricos son obstáculo para el seguimiento de 
Cristo. Santiago critica las actitudes de soberbia de los ricos cristianos que "buscaban ser recibidos con gentileza y atenciones especiales" (Brown, 2012, p. 951).

Sin embargo, en el mismo encuentro celebrativo, los pobres son tratados con desprecio y repudio. Tales situaciones discriminatorias creaban dificultades en la manera de creer (Sant 2,4; Lugo y López, 2008, p. 89). Del mismo modo los marginados eran llevados a los tribunales; pero, de ahora en adelante, por causa del Evangelio, todos son hermanos (Sant 2,5). Para Santiago, la fe precisa de obras (Sant 2,14). La exhortación es dirigida a los ricos que no quieren cambiar sus actitudes y, aun así, continúan frecuentando la Asamblea («ekklesia») a la espera de los favores divinos. "La Carta de Santiago es heredera de una larga y venerable tradición bíblica: la preferencia de Dios por los pobres y los débiles" (Lugo y López, 2008, p. 89).

La pobreza es una consecuencia del rechazo social. Jesús enseña que la opción preferencial por los pobres es una exigencia moral que significa acoger con afecto y cariño al que ha sido marginado por las estructuras sociales. Pablo recuerda el deber que deben asumir los hermanos entre sí. La comunidad no puede estar dividida por causa de los bienes o de las condiciones sociales. Santiago recuerda que el culto demuestra la celebración de unas actitudes hacia los más necesitados. Las obras de compasión y de cuidado hacia los rechazados por la sociedad son las que legitiman el seguimiento de Cristo. Ser cristiano es, entonces, ser y hacer como Jesús.

\section{Desafíos teológicos de la opción preferencial por los pobres}

El tercer paso metodológico que propone Clodovis Boff consiste en la mediación práctica. La lectura de las condiciones socio-analíticas y la comprensión de tales acontecimientos a la luz de las Escrituras invitan al creyente a asumir acciones concretas que permitan la transformación de la sociedad y que apunten a la búsqueda del Reino de Dios. La inquietud por transformar la realidad se traza ante la urgencia de poner en práctica acciones que permitan la inclusión de hombres y mujeres que han sido marginados por sus condiciones de pobreza. Dios se manifiesta en la opción por los pobres, de modo que optar por el Señor es optar por la pobreza.

¿Cuáles serían los desafíos teológicos que presenta la opción preferencial por los pobres? La mediación práctica implica asumir acciones concretas por medio 
de las cuales se pueda vivir el amor de Dios. El papa Francisco ha rescatado en su Carta Encíclica Laudato Si' (2005) la necesidad de revitalizar las relaciones que el ser humano tiene consigo mismo, con los demás, con la naturaleza y con Dios. La enseñanza que propone Francisco consiste en el cuidado de los recursos que tenemos y que son clara manifestación del amor de Dios. Dios ha ofrecido por amor sus dones al ser humano; pero los deseos particulares han deteriorado los recursos de nuestra casa común. ¿Cómo podemos vivir tranquilamente cuando nuestras relaciones han sido fragmentadas por los deseos de riqueza insaciable?

La pobreza nos recuerda nuestra propia naturaleza en la que somos totalmente indigentes, necesitados y vulnerables. El ser humano se sabe frágil, necesitado de los demás (Torralba, 2010); de manera que requiere establecer relaciones en las que pueda suplir sus necesidades. En la alteridad el ser humano identifica su propia identidad. Cada persona elabora complejas relaciones consigo mismo, con los demás, con el entorno y con Dios y las establece por la necesidad de plenitud, de trascendencia. El desafío teológico consiste en ver que cuanto posee el ser humano son mediaciones que el Señor le ofrece como dones para alcanzar la realización.

Para la teología es fundamental el encuentro de la persona con Dios. La opción por los pobres no puede reducirse a una ideología, porque en la pobreza se presenta el encuentro con el Señor. El cuidado por los pobres es la mejor manera de adorar al Señor. ¿Por qué critican tanto los profetas a quienes se limitan a ofrecer becerros en espléndidas liturgias? ¿Por qué los discursos contra reyes y jueces? ¿Por qué las amonestaciones de Jesús a escribas y fariseos? ¿Cuál es el motivo de las exhortaciones paulinas en contra de los ciudadanos acomodados? Ahí surge el primer desafío teológico: lograr un encuentro auténtico con el Señor que solo se presenta en la pobreza.

El llamado al cuidado de los dones que ofrece el Señor para la subsistencia es otro desafío teológico. Las relaciones consigo mismo, con los demás, con el entorno y con Dios implican reconocer que Dios se presenta en cada una de estas instancias; pero, a pesar de la magnanimidad divina, tales dones no son en absoluto eternos: requieren del cuidado responsable. El cuidado de las personas y de los bienes es una insistencia de las Escrituras. El papa Francisco recuerda cómo lamentablemente los dones de la creación han sido desperdiciados. "Muchas ciudades son grandes estructuras ineficientes que gastan energía y agua en exceso" (2015, p. 44). El uso desmedido de los recursos naturales atenta contra la vida de otros seres. 
Este llamado a cuidar los recursos que pasan por nuestras manos es una responsabilidad de cada ciudadano: la opción por los pobres como manifestación del amor de Dios acontece con actos de responsabilidad en el cuidado del agua, del ambiente, de los alimentos, de los hábitats naturales, del buen uso de la tierra, de la implementación de prácticas saludables con el entorno, con los demás y con nosotros mismos. El cuidado de nuestra casa común es un desafío teológico en el cual reconocemos la presencia de Dios que desea extender su Reino a los más necesitados. "Optar por los pobres implica una práctica: significa asumir el lugar del pobre, su causa, su lucha y, en el límite, su destino muchas veces trágico" (Boff, L, 2004, p. 150).

\section{Conclusión}

A lo largo de toda esta discusión se pueden concluir tres puntos principales. El primero: la opción preferencial por los pobres surge en medio de las inquietudes que vive un pueblo marginado por la injusticia y la explotación. Las situaciones históricas, sociales y económicas llevaron a diversos actores eclesiales a plantearse serios cuestionamientos en relación al origen de las graves consecuencias que desataron finales catastróficos. La pregunta resulta ser más estructural porque no se satisface recibir como respuesta los nombres de supuestos responsables, sino que busca ver cuál es la causa antropológica que está en el fondo de todas estas difíciles situaciones.

Segundo. En la Escritura Dios hace una opción preferencial por los pobres porque ellos han logrado el desprendimiento necesario para hacer de Dios su opción fundamental. La opción preferencial por los pobres orienta, en definitiva, a un cambio estructural de actitudes; debe modificar la ética humana para establecer una ética centrada en el Señor. Es así como los relatos del Antiguo Testamento exponen la lucha que tiene el pueblo que hasta el exilio se consideraba seguro y creía tener todas las garantías para llevar una vida bendecida. Sin embargo, tanta seguridad llevó al olvido de las leyes y mandatos que ordenan el cuidado de los pobres y marginados.

Finalmente, podemos concluir que la opción preferencial por los pobres es una iniciativa del amor de Dios que ilumina la vida del cristiano, y que, por tanto, debe llevar a un compromiso fiel en las actitudes éticas centradas en la figura de Cristo, nuestro Señor. En el momento histórico que vive nuestra tierra no se 
puede olvidar que los pobres están ahí esperando nuestro favor, nuestra misericordia. Dios se presenta en medio de los pobres para que los atendamos, cuidemos y centremos en ellos nuestro proyecto de vida cristiana. Un seguimiento honesto del Señor solo será posible si el cristiano asume en su vida práctica actitudes en favor de los más necesitados.

América Latina es confesada por la mayoría de sus habitantes como una tierra de cristianos; sin embargo, vive situaciones de extrema pobreza, opresión e injusticia. Esta parte del continente cuenta con los más altos niveles de desigualdad: los ricos más ricos del mundo viven aquí de la misma forma que los pobres más pobres se alojan en las periferias de las grandes ciudades. La exigencia moral de la opción preferencial por los pobres no puede ser vista como un bello discurso de las conferencias episcopales de América Latina que se queda en el papel. Los cristianos deben modificar su modo de proceder para que se adecúe al cuidado de los más necesitados. Solo así será genuino el seguimiento de Dios.

\section{Referencias}

Aguirre, R., Bernabé, C., y Gil, C. (2014). Guías de lectura de los evangelios de Mateo, Marcos y Lucas. Estella, España: Verbo Divino.

Amsler, S., Asurmendi, J., Auneau, J., y Martin-Achard, R. (1992). Os profetas e os livros proféticos. Tradução de Benôni Lemos. São Paulo, Brasil: Paulinas.

Andiñach, P. (2006). El libro del Éxodo. Salamanca, España: Sígueme.

Barbaglio, G. (1992). Pablo de Tarso y los orígenes cristianos. Salamanca, España: Sígueme.

Barbaglio, G. (1993). 1-2 Coríntios. São Paulo, Brasil: Paulinas.

Barbaglio, G. (1995). La prima lettera ai Corinzi, Bologna, Italia: Edizioni Dehoniane.

Boff, L. (1986). Teología desde el lugar del pobre, Santander, España: Sal Terrae.

Boff, L. (1990). Epistemología y método de la teología de la liberación. En Ellacuría B., I. y Sobrino, J. Mysterium Liberationis: Conceptos fundamentales de la teología de la liberación, 1(pp. 79-113). Madrid, España: Trotta.

Boff, L. (2004). Ecologia: grito da terra, grito dos pobres, Rio de Janeiro, Brasil: Sextante.

Brown, R. (2012). Introdução ao Novo Testamento. São Paulo, Brasil: Paulinas.

CELAM. (1979). Tercera Conferencia General del Episcopado Latinoamericano Tercera parte. Comunión y participación. Puebla, México. Recuperado de: http:// www.celam.org/doc_conferencias/Documento_Conclusivo_Puebla.pdf. 
Comblin, J. (1990). Espíritu Santo. En Ellacuría B., I. y Sobrino, J. Mysterium Liberationis: Conceptos fundamentales de la teología de la liberación, (pp. 619-642). Madrid, España: Trotta.

Concilio Vaticano II. (1968). Constitución Dogmática sobre la Iglesia Lumen Gentium en Documentos del Vaticano II constituciones, decretos, declaraciones. Madrid, España: BAC.

Croatto, J. (1995). Historia de salvación: La experiencia religiosa del pueblo de Dios. Estella, España: Verbo Divino.

Fernández, J. L. (2007). El Dios de los pobres. Salamanca, España: Secretariado Trinitario.

Francisco. (2014). Mensaje del santo padre Francisco para la XXIX Jornada Mundial de la Juventud 2014. Recuperado de: http://w2.vatican.va/content/francesco/it/ messages/youth/documents/papa-francesco_20140121_messaggio-giovani_2014. html. 21 de enero de 2014.

Francisco. (2015). Carta Encíclica Laudato Si' "alabado seas", sobre el cuidado de la casa común. Bogotá D. C., Colombia: Ediciones Paulinas.

García López, F. (2004). El Pentateuco. Estella, España: Verbo Divino.

García Trapiello, J. (1977). El problema de la moral en el Antiguo Testamento. Barcelona, España: Herder.

Gelin, A. (1963). Las ideas fundamentales del Antiguo Testamento. Bilbao, España: Desclée de Brouwer.

González Ruiz, J. M. (1988). El Evangelio de Pablo. Santander, España: Sal Terrae.

Juan XXIII. (1989). Citado por Libânio, J. Teología de la liberación: guía didáctica para su estudio. Santander España: Sal Terrae.

Konings, J. (2005). Evangelho segundo João: amor e fidelidade, São Paulo, Brasil: Loyola.

Libânio, J. (1989). Teología de la liberación: guía didáctica para su estudio. Santander, España: Sal Terrae.

Lohfink, N. (1987). Biblia y opción por los pobres. Selecciones de Teología, 26(104), 29-38. Recuperado de: http://www.seleccionesdeteologia.net/selecciones/llib/ vol26/104/104_lohfink.pdf

Lohfink, N. (1998). La opción por los pobres. México D. F., México: Universidad Iberoamericana.

Lois, J. (1991). Opción por los pobres. En Vigil J. M. (Ed.). La opción por los pobres. (pp. 9-18). Santander, España: Sal Terrae.

Lugo, R. H., y López R., R. (2008). Hebreos y Cartas Católicas: Santiago, 1 y 2 Pedro, Judas, 1, 2 y 3 Juan. Estella, España: Verbo Divino.

Luz, U. (2003). El Evangelio según san Mateo: Mt 18-25. (Vol. III). Salamanca, España: Sígueme. 
Maduro, O. (1981). Religião e luta de classes. Petrópolis, Brasil: Vozes.

Malina, B., y Rohrbaugh, R. (1996). Los evangelios sinópticos y la cultura mediterránea del siglo I: comentario desde las ciencias sociales. Estella, España: Verbo Divino.

Marcus, J. (2010a). El Evangelio según Marcos: (Mc 8-16). Salamanca, España: Sígueme.

Marcus, J. (2010b). El Evangelio según Marcos: (Mc 1-8). Salamanca, España: Sígueme.

Martimort, A. G. (1987). La Iglesia en oración: introducción a la liturgia. Barcelona, España: Herder.

Moreno R., F. (1986). Teología moral desde los pobres. La moral en la reflexión teológica desde América Latina. Madrid, España: Perpetuo Socorro.

Novoa, C. (2009). Una perspectiva latinoamericana de la teología moral. Bogotá D. C., Colombia: Pontificia Universidad Javeriana, Facultad de Teología.

Oliveros R. (1989). Teología de la liberación: su génesis, crecimiento y consolidación (1968-1988). En Gutiérrez, G., Boff, L. O., Duquoc, C. O., Libânio, J. S., Sobrino, J. S., Alfaro, J. S., y Vidal García, M. Teología y liberación. Perspectivas y desafíos, ensayos en torno a la obra de Gustavo Gutiérrez, (pp. 89-107). Lima, Perú: Instituto Bartolomé de las Casas, CEP.

Parker G., C. (2014). Pluralismo religioso y cambio de paradigma identitario en el campo político latinoamericano actual. En Ameigeiras, A. R. (Comp.) Símbolos, rituales religiosos e identidades nacionales: los símbolos religiosos y los procesos de construcción política de identidades en Latinoamérica, (pp. 39-69). Buenos Aires, Argentina: CLACSO.

Pikaza, J. (1978). A teologia de Lucas. São Paulo, Brasil: Paulinas.

Pikaza y De La Calle, F. (1980). Teología de los evangelios de Jesús. Salamanca, España: Sígueme.

Pikaza, X. (1994). Para leer la historia del pueblo de Dios. Estella, España: Verbo Divino.

Revista IHU. (2009). Dom Helder Câmara e o Pacto das Catacumbas (16 de noviembre de 1965). Recuperado de: http://www.ihu.unisinos.br/noticias/ noticias-arquivadas/19769-dom-helder-e-o-pacto-das-catacumbas.

Sánchez N., J. L. (2015). Aproximación a una teología de las religiones. Madrid, España: BAC.

Schökel, A. y Sicre, J. L. (1980a). Profetas I. Madrid, España: Cristiandad.

Schökel, A. y Sicre, J. L. (1980b). Profetas II. Madrid, España: Cristiandad.

Schrage, W. (1987). Ética del Nuevo Testamento. Salamanca, España: Sígueme.

Sicre, J. L. (1985). "Con los pobres de la tierra": La justicia social en los profetas de Israel. Madrid, España: Cristiandad.

Sicre, J. L. (1986). Los profetas de Israel y su mensaje. Madrid, España: Cristiandad.

Sicre, J. L. (1996). El cuadrante, parte I: la búsqueda. Estella, España: Verbo Divino. 
Sicre, J. L. (1996). El cuadrante, parte II: la apuesta. Estella, España: Verbo Divino.

Sicre, J. L. (1998). Profetismo en Israel. Estella, España: Verbo Divino.

Stegemann, E., y Stegemann, W. (2001). Historia social del cristianismo primitivo. Estella, España: Verbo Divino.

Suaiden, S. (2007). A dimensão profética e crítica da fé profética de Israel: Um estudo de Miquéias 6,1-8. En Kaefer, J. A., \& Jarschel, H. (orgs.), Dimensões sociais da fé do Antigo Israel: Uma homenagem a Milton Schwantes, (pp. 121-139). São Paulo, Brasil: Paulinas.

Torralba R., F.(2010). Hacia una antropología dela vulnerabilidad. Revista Forma, 2, 25-32. Recuperado de: www.raco.cat/index.php/Forma/article/download/216306/287078

Theissen, G. (2002). La religión de los primeros cristianos. Salamanca, España: Sígueme.

Vermeylen, J. (1990). El Dios de la Promesa y el Dios de la Alianza. Santander, España: Sal Terrae.

Vitório, J. (2003). ‘Os olhos do Senhor estão sobre o reino pecador' (Am 9,8) - Profetismo e História na pregação de Amós. En Faria, J. de F. (Org.). História de Israel e as pesquisas mais recentes, (pp. 125-143). Petrópolis, Brasil: Vozes.

Vitório, J. (2004). Poder da Fé-Poder das Armas. A experiencia de Isaías, de. Jesús e dos cristãos, Convergência, 372(04), 212-229.

Walter, E. (1971). Primera Carta a los Corintios. Barcelona: España Herder.

Wénin, A. (2004). La serpiente, el novillo y el baal. Selecciones de teología, (169), 29-38. Recuperado de http://www.seleccionesdeteologia.net/selecciones/llib/vol43/169/ 169_wenin2.pdf 